\title{
Questionnaire Based Study about Association between Blood Oxygen Level and Mysophobia
}

\author{
Muhammad Imran Qadir and Iqra Ali Yameen* \\ Institute of Molecular Biology \& Biotechnology, Multan Pakistan \\ *Corresponding author: Iqra Ali Yameen, Institute of Molecular Biology \& Biotechnology, Multan Pakistan
}

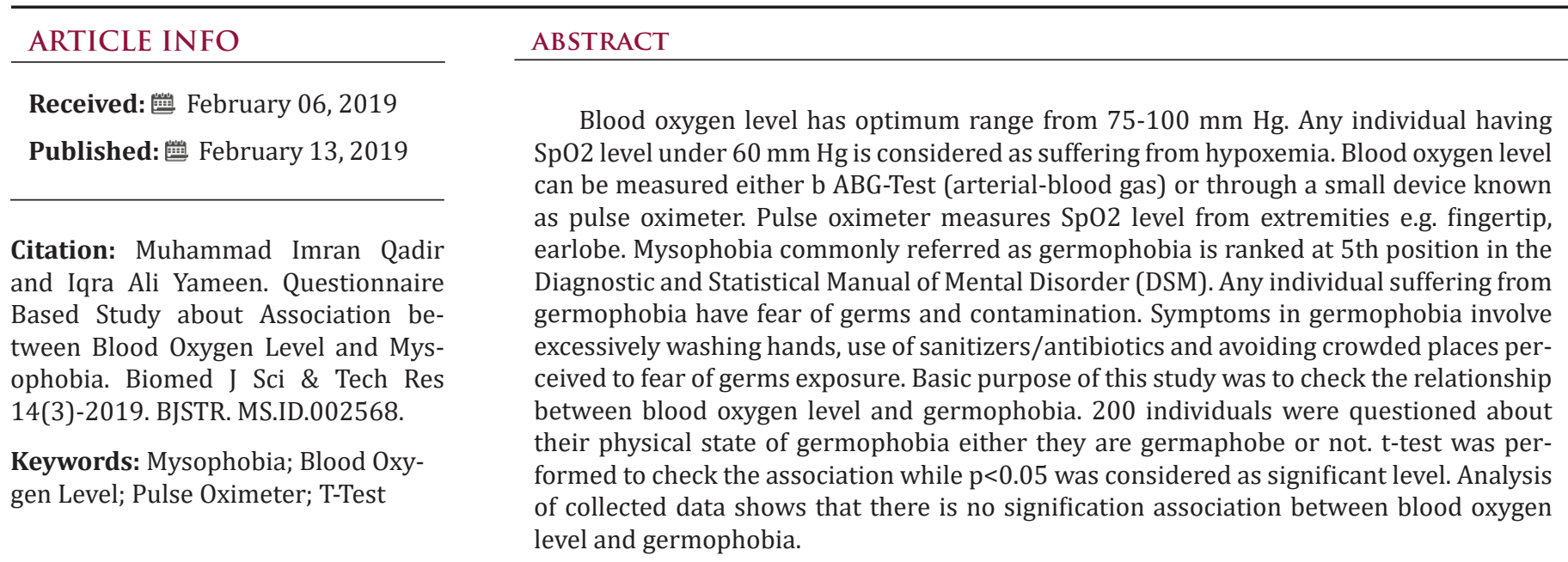

\section{Introduction}

Optimum level of arterial oxygen in a healthy individual ranges from 75-100 millimeter of mercury (mm $\mathrm{Hg}$ ). Any individual with oxygen level under $60 \mathrm{~mm} \mathrm{Hg}$ is suffering from hypoxemia. Hypoxemia is related to low oxygen level in blood especially in arteries, that results in trouble breathing and nausea. Blood oxygen level can be measured by Arterial-Blood Gas Test (ABG-Test). ABG test measures the level of oxygen and carbon dioxide by taking blood sample from arteries. Sometimes the ABG- test can be difficult to do at home therefore, a small device known as pulse oximeter is commonly used. Pulse oximeter is a small clip like device that does not require blood samples, it measures the oxygen level with special sensors when attached to fingertip, toe or ear lobe [1]. Although pulse oximeter is easy to use and very convenient but it is less accurate than $A B G$ as it measure the saturation of peripheral oxygen (Sp02) from extremities, results may differ due to external factors e.g. poor circulation, dirty fingers, nail polish and standing position [2]. Normal SpO2 level measured by pulse oximeter ranges from $95-100 \%$, while individuals with less than $90 \%$ are considered with lower oxygen level or suffering from hypoxemia [3].
Mysophobia sometimes also referred as germophobia, verminophobia and germaphobia is the distress about germs and contamination. Germophobia falls at fifth position in the Diagnostic and Statistical Manual of Mental Disorder (DSM) [4]. In 1879, William A. Hammond first time used the terminology germophobia while observing obsessive-complex disorder (OCD) of washing hands among his patients [5]. While being a germaphobe not certainly mean that individual is suffering from OCD until diagnosed with excessive and unreasonable standards of hygienic environment [6]. An individual is regarded as germaphobe if DSM-5 lasts for a period of 6 months or more. Social Phobia Inventory (SPIN) questionnaire is used to identify phobias [7]. Symptoms related to germophobia includes intensive fear of germs and being contaminated that disturb psychological heath [8]. Behavioral symptoms include excessively washing hands, use of sanitizers/antibiotics and avoiding crowded places perceived to fear of germs exposure [9].

Common physical symptoms examined in an individual suffering from germophobia are rapid heartbeat, difficulty in breathing, muscle tension and sometime chills. Genetic linkage of family history, environment issues, brain health and many other factors are 
believed to be the main sources of germophobia [10]. Purpose of this study was to evaluate the effect of germophobia on normal oxygen level (Sp02). To check the correlation between germophobia and saturation of peripheral oxygen that will help in estimating the body response against germophobia.

\section{Materials and Methods}

\section{Project Design}

A questionnaire was designed to check the correlation between germophobia and blood oxygen level. 200 individuals from IMBB (Institute of Molecular Biology \& biotechnology) department of Bahauddin Zakariya University were questioned either they are suffering from germophobia or not. Their blood oxygen level was measured by pulse oximeter device, it checks the saturation of peripheral oxygen $\left(\mathrm{SpO}_{2}\right)$ from fingertip. $\mathrm{SpO}_{2}$ level was examine in both male and female individuals.

\section{Measurement of Peripheral Oxygen Saturation}

Saturation of peripheral oxygen $\left(\mathrm{SpO}_{2}\right)$ was measured in the blood by the pulse oximeter. It can be calculated with pulse oximetry according to the following formula:

$$
\mathrm{S}_{\mathrm{p}} \mathrm{O}_{2}=\frac{\mathrm{HbO}_{2}}{\mathrm{HbO}_{2}+\mathrm{Hb}}
$$

$\mathrm{HbO} 2$ is oxygenated hemoglobin and $\mathrm{Hb}$ is deoxygenated hemoglobin

\section{Statistical Analysis}

M Stat software was used to analyze the results. Student's t-test was performed. $\mathrm{p}<0.05$ was considered as significant.

\section{Results and Discussion}

The correlation between peripheral oxygen saturation and germophobia is shown in Table 1. T-test was performed to check the impact of mysophobia on blood oxygen level. 200 individuals were questioned while the p-value less than 0.05 was considered as significant. Analysis of collected data presents that there is no impact of blood oxygen level on the germophobia. p-value of the collected data for both male and female was greater than 0.05 , which characterizes that it is non-significant. Out of 200 individuals there were 60 males and 140 females. Fifty male out of 60 individuals were germaphobe while 10 were not suffering from germophobia. 91 female out of 140 had fear of germs, while 49 were non-germaphobe. Among 200 individuals, 141 have germophobia while 59 were normal. $83.3 \%$ males and $65 \%$ females said that they are germaphobe, while $16.7 \%$ male and $35 \%$ female said that they are non germaphobe. Out of 100 , total $70.5 \%$ individuals said they are germaphobe while $59 \%$ are not. p-value for male, female and both was $0.13,0.46$ and 0.65 respectively which is greater than significant value of 0.05 , hereafter shows that results are non-significant for both male and female categories. Percentage of mysophobic and non-mysophobic individuals is shown in Table 2.

Table 1: Association between blood oxygen level (Mean \pm S.D) and mysophobia.

\begin{tabular}{|c|c|c|c|}
\hline Gender & Germaphobe & Non-germaphobe & p-value \\
\hline Male & $96 \pm 5.283$ & $97.7 \pm 2.410$ & 0.13 \\
\hline Female & $95.96 \pm 7.210$ & $95.14 \pm 5.912$ & 0.46 \\
\hline Both & $95.97 \pm 6.60$ & $95.57 \pm 5.555$ & 0.65 \\
\hline
\end{tabular}

Note: Non-significant (where $\mathrm{p}>0.05)$.

Table 2: Percentage of mysophobic and non-mysophobic individuals.

\begin{tabular}{|c|c|c|}
\hline Gender & Yes & No \\
\hline Male & $83.3 \%$ & $16.7 \%$ \\
\hline Female & $65 \%$ & $35 \%$ \\
\hline Total & $70.5 \%$ & $29.5 \%$ \\
\hline
\end{tabular}

Note: Non-significant (where $\mathrm{p}>0.05)$.

\section{Conclusion}

In this study a correlation between mysophobia and blood oxygen level was measured. 200 individuals were questioned either they have germophobia or not, while their oxygen level was measured by pulse oximeter. Analysis and prediction of collected data shows that there is no significant association between germophobia and blood oxygen level. It shows that blood oxygen level have no clear impact on the germophobia as the calculated p-value was greater than 0.05 , a standard value of significance.

\section{References}

1. Mortz MS (1999) System for pulse oximetry $\mathrm{SpO}_{2}$ determination: Google Patents.

2. Medzhitov R, Schneider DS, Soares MP (2012) Disease tolerance as a defense strategy. Science, 335(6071): 936-941.

3. Logothetis NK (2002) The neural basis of the blood-oxygen-leveldependent functional magnetic resonance imaging signal. Philosophical Transactions of the Royal Society of London B: Biological Sciences 357(1424): 1003-1037.

4. Efremova M (2001) Obsessive-phobic disorders with the phenomena of mysophobia in slowly progressing schizophrenia. Zhurnal nevrologii i psikhiatrii imeni SS Korsakova 101(2): 12-17. 
5. LAWRANCE G (1952) Mysophobia. The Medical journal of Australia 1(4): 125-125.

6. Schneck JM (1966) Hypnoanalytic elucidation of a childhood germ phobia. International Journal of Clinical and Experimental Hypnosis 14(4): 305-307.

7. David JdL, McTiernan G, Strauss NH (1981) A Case of Severe ObsessiveCompulsive Behaviour Treated by Nurse Therapists in an In-Patient Unit. Behavioural and Cognitive Psychotherapy 9(1): 46-54.

8. Tebbe-Grossman J, Gardner MN (2011) Germ Free: Hygiene History and Consuming Antimicrobial and Antiseptic Products. Innate Immune

\section{ISSN: 2574-1241}

DOI: 10.26717.BJSTR.2019.14.002568

Iqra Ali Yameen. Biomed J Sci \& Tech Res

(C) This work is licensed under Creative

Submission Link: https://biomedres.us/submit-manuscript.php
System of Skin and Oral Mucosa: Properties and Impact in Pharmaceutics, Cosmetics, and Personal Care Products p. 1-42.

9. Bajwa M, Chaudhry KA, Saeed R (2014) Prevalence and factors associated with phobias among women. Journal of Psychiatry 15(2): 140-145.

10. Bussing R, Levin GM (1993) Methamphetamine and fluoxetine treatment of a child with attention-deficit hyperactivity disorder and obsessive-compulsive disorder. Journal of child and adolescent psychopharmacology 3(1): 53-58.

BIOMEDICAL
RESEARCHES $\quad \begin{aligned} & \text { Assets of Publishing with us } \\ & \text { - Global archiving of articles }\end{aligned}$

